Article

\title{
Dectin-1-Mediated Pathway Contributes to Fusarium proliferatum-Induced CXCL-8 Release from Human Respiratory Epithelial Cells
}

\author{
Chang-Ching Yeh ${ }^{1,2,3}$, Huann-Cheng Horng ${ }^{1,3,4}$, Hong Chou ${ }^{5}$, Hsiao-Yun Tai ${ }^{5}$, \\ Horng-Der Shen ${ }^{5}$, Shie-Liang Hsieh ${ }^{2,5,6}$ and Peng-Hui Wang 1,2,3,7,* \\ 1 Department of Obstetrics and Gynecology, Taipei Veterans General Hospital, Taipei 112, Taiwan; \\ ccyeh39@gmail.com (C.-C.Y.); hchorng@vghtpe.gov.tw (H.-C.H.) \\ 2 Institute of Clinical Medicine, National Yang-Ming University, Taipei 112, Taiwan; \\ slhsieh@gate.sinica.edu.tw \\ 3 Department of Obstetrics and Gynecology, National Yang-Ming University, Taipei 112, Taiwan \\ 4 Institute of BioMedical Informatics, National Yang-Ming University, Taipei 112, Taiwan \\ 5 Department of Medical Research, Taipei Veterans General Hospital, Taipei 112, Taiwan; \\ chou125@yahoo.com.tw (H.C.); hytai@vghtpe.gov.tw (H.-Y.T.); hdshen@vghtpe.gov.tw (H.-D.S.) \\ 6 Genomics Research Center, Academia Sinica, Taipei 11529, Taiwan \\ 7 Department of Medical Research, China Medical University Hospital, Taichung 40447, Taiwan \\ * Correspondence: phwang@vghtpe.gov.tw; Tel.: +886-2-2875-7566
}

Academic Editors: Paul R. Reynolds and Benjamin T. Bikman

Received: 12 January 2017; Accepted: 10 March 2017; Published: 13 March 2017

\begin{abstract}
Fusarium species are causative agents of human respiratory disorders and are distributed widely in our environment. Little is known of their interaction with human respiratory epithelial cells, which may contribute to allergic airway responses. In this study, we report on the release of C-X-C motif chemokine ligand 8 (CXCL-8) from human bronchial epithelial BEAS-2B cells upon stimulation with Fusarium proliferatum extracts. F. proliferatum-induced cytokine release from BEAS-2B cells was determined by cytokine array and CXCL-8 enzyme-linked immunosorbent assay (ELISA) kits. Blocking antibodies and signaling pathway inhibitors were employed to delineate cell surface receptors and signaling pathways participating in CXCL-8 release. F. proliferatum extracts induced the release of CXCL-8 in a time-dependent manner. The dectin-1 receptor ligands, curdlan and laminarin, reduced CXCL-8 release. Cells pre-treated with anti-Dectin-1 antibodies $(2 \mu \mathrm{g} / \mathrm{mL})$ decreased CXCL-8 release by $24 \%$. Furthermore, F. proliferatum-stimulated CXCL-8 release was reduced by $32 \%, 53 \%-81 \%, 40 \%$ and $26 \%$ after BEAS-2B cells were pretreated with activation inhibitors of spleen tyrosine kinase (Syk) — piceatannol—, mitogen-activated protein kinases (MAPKs) —PD98059, U0126, SB202190, SP600125-, phosphatidylinositol-3-kinase (PI3K)—LY294002_and nuclear factor $\kappa$-light-chain-enhancer of activated B cells (NF- $\mathrm{KB}$ )—BAY117082—, respectively. These results suggest that Dectin-1-mediated activation of the Syk, MAPKs, PI3K and NF- $\mathrm{KB}$ signaling pathways contributes to F. proliferatum-stimulated CXCL-8 release from BEAS-2B cells and provides an important basis for developing novel therapeutic strategies in clinical allergy.
\end{abstract}

Keywords: Fusarium proliferatum; CXCL-8; respiratory epithelial cells; Dectin-1

\section{Introduction}

Fungi are ubiquitous in our living environment and are important causative agents of human respiratory atopic diseases [1-3]. Airway epithelial cells are primordial cells that respond to inhaled potential allergens and irritants and act as a physical barrier, which may also secret mediators that 
contribute to the pathogenesis of respiratory atopic disorders [4-7]. However, information regarding interactions between airborne fungi and human airways is still limited.

Airborne fungi such as Fusarium may play significant roles in clinical allergy studies [8]. For example, results from Stroud et al. [9] showed that reactivity to fungi was found in approximately $65 \%$ of chronic rhinitis patients and reactions to the Fusarium (58\%), Alternaria (39\%) and Pullularia $(38 \%)$ species were particularly common. We have previously identified transaldolase as an important allergen of Fusarium proliferatum [8], and a vacuolar serine proteinase of F. proliferatum has also recently been characterized as a major allergen [10]. However, interactions among F. proliferatum and human respiratory epithelial cells are still largely unknown.

We analyzed the cytokine release profile of human bronchial epithelial BEAS-2B cells upon F. proliferatum extract stimulation and examined the potential mechanism of $\mathrm{C}-\mathrm{X}-\mathrm{C}$ motif chemokine ligand 8 (CXCL-8) release from these cells. Our results showed that the Dectin-1-mediated pathway, contributes to CXCL-8 release from F. proliferatum-stimulated BEAS-2B cells.

\section{Results}

\subsection{Fusarium proliferatum-Induced Cytokines Release by BEAS-2B Cells}

To investigate the profile of cytokine release from human bronchial epithelial cells in response to F. proliferatum stimulation, BEAS-2B cells were exposed to F. proliferatum extracts $(100 \mu \mathrm{g} / \mathrm{mL})$ for $24 \mathrm{~h}$. The concentration of interleukin (IL)-1A, IL1- $\beta$, IL-2, IL-4, IL-6, IL-8/CXCL-8, IL-10, IL-12, IL-17A, interferon $\gamma$ (INF- $\gamma)$, tumor necrosis factor $\alpha$ (TNF- $\alpha$ ) and granulocyte-macrophage colony-stimulating factor (GM-CSF) in cultured supernatants was analyzed with a Cytokines Multi-Analyte ELISArray Kit. Compared to the control cells, BEAS-2B cells treated with F. proliferatum extracts showed a significant increase in CXCL-8 release (Figure 1). No significant differences were observed for the release of other mediators between treated and unexposed cells (Figure 1). CXCL-8 is an important chemotactic cytokine in human lung inflammation, therefore, we focused on the mechanism of CXCL-8 release from BEAS-2B cells.

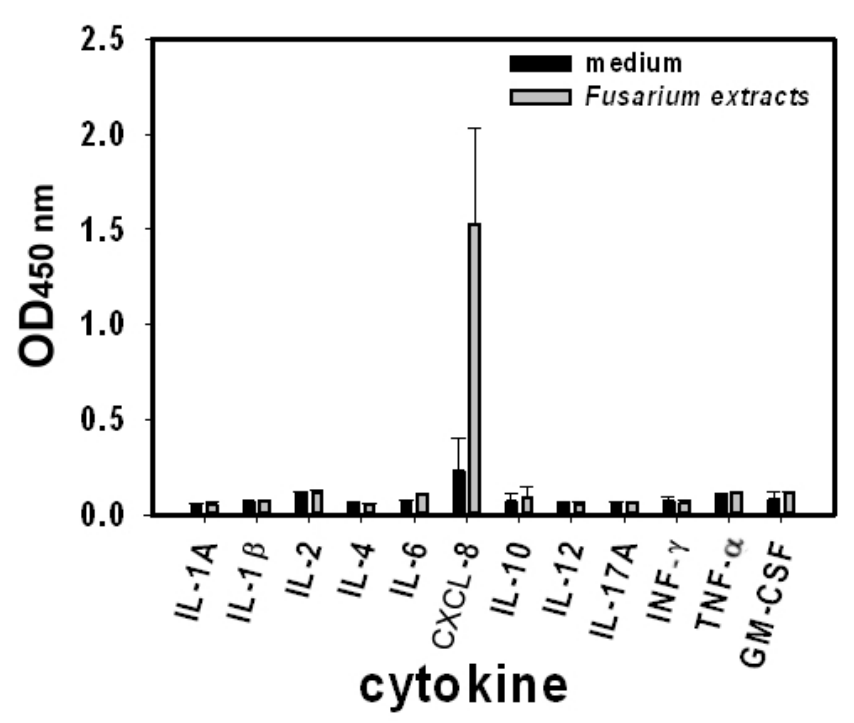

Figure 1. Fusarium proliferatum-induced cytokines released from human lung epithelial BEAS-2B cells. BEAS-2B cells were stimulated with F. proliferatum extracts $(100 \mu \mathrm{g} / \mathrm{mL})$ and were incubated for $24 \mathrm{~h}$ before cytokine release in the supernatants was analyzed with a Cytokines Multi-Analyte ELISArray Kit. Data shown here represent two independent experiments performed in duplicate and are presented as the mean optical density (OD) at $450 \mathrm{~nm}$ of two experiments \pm standard deviations. IL: Interleukin; CXCL-8: C-X-C motif chemokine ligand 8; INF- $\gamma$ : Interferon $\gamma$; TNF- $\alpha$ : Tumor necrosis factor $\alpha$; GM-CSF: granulocyte-macrophage colony-stimulating factor. 
BEAS-2B cells were exposed to F. proliferatum extracts $(100 \mu \mathrm{g} / \mathrm{mL})$ and CXCL-8 release was examined at 2, 4, 8 and $24 \mathrm{~h}$ intervals. Compared to un-stimulated cells, the level of CXCL-8 in the cultured supernatant was elevated as early as $4 \mathrm{~h}$ after exposure to F. proliferatum extracts and continued to increase (Figure 2).

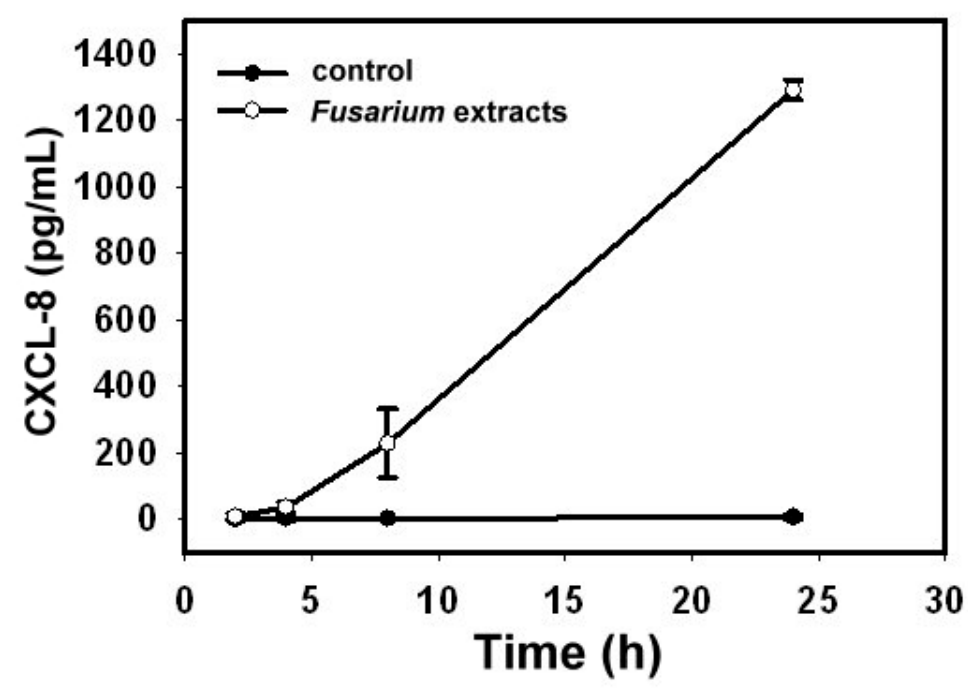

Figure 2. F. proliferatum induces CXCL-8 release in a time-dependent manner. BEAS-2B cells were treated with F. proliferatum extracts $(100 \mu \mathrm{g} / \mathrm{mL})$ for $2,4,8$ and $24 \mathrm{~h}$. The level of CXCL-8 in the culture medium was determined by enzyme-linked immunosorbent assay (ELISA). The data shown represent three independent experiments performed in duplicate and are presented as the mean of three experiments \pm the standard deviations.

BEAS-2B cells were also exposed to F. proliferatum extracts at concentrations ranging from 50 to $150 \mu \mathrm{g} / \mathrm{mL}$ for $24 \mathrm{~h}$. Our results showed that F. proliferatum induced CXCL-8 release in a dose-dependent manner [11].

\subsection{The Role of $\beta$-Glucan Structure in Fusarium proliferatum-Induced CXCL-8 Release by BEAS-2B Cells}

$\beta$-Glucan is the main component of fungal cell walls. In this study, we focused on the role of Fusarium-derived $\beta$-glucan moieties interacting with BEAS-2B cells. Laminarin $(10 \mu \mathrm{g} / \mathrm{mL})$ and curdlan $(10 \mu \mathrm{g} / \mathrm{mL}), \beta$-glucan receptor ligands, were pre-incubated individually with BEAS-2B cells for $1 \mathrm{~h}$ before stimulating with F. proliferatum extracts. We found that curdlan and laminarin significantly reduced CXCL-8 release from F. proliferatum-treated BEAS-2B cells to $20 \%$ and 53\% of the controls without incubation with inhibitors, respectively (Figure 3a). Incubation of BEAS-2B cells with curdlan or laminarin alone did not affect CXCL-8 release (data not shown). Furthermore, two different concentrations of curdlan ( 2 or $10 \mu \mathrm{g} / \mathrm{mL}$ ) were used in the inhibition studies. The data (Figure $3 \mathrm{~b}$ ) showed that curdlan decreased F. proliferatum extracts-induced CXCL- 8 release to $46 \%$ and $25 \%$ of the controls without incubation with inhibitors, respectively (Figure 3b). 


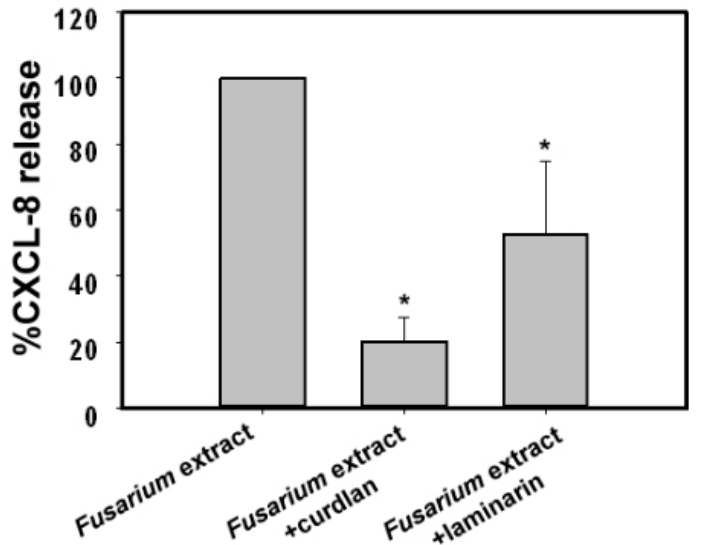

(a)

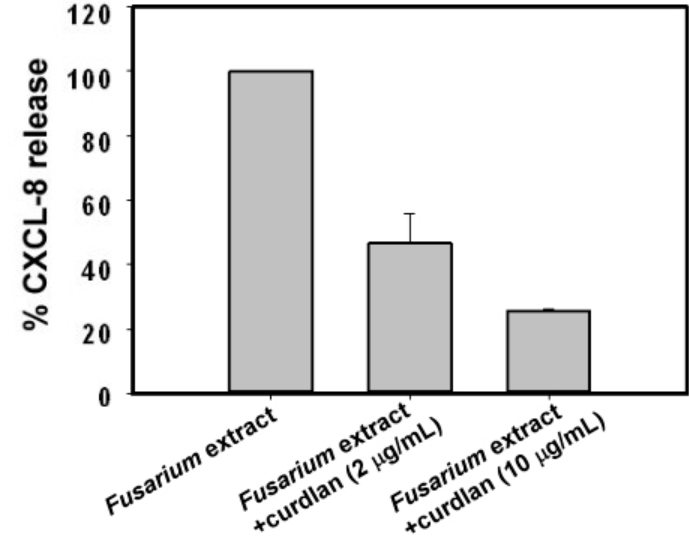

(b)

Figure 3. Effect of $\beta$-glucan on CXCL-8 release. (a) Curdlan $(10 \mu \mathrm{g} / \mathrm{mL})$ or laminarin $(10 \mu \mathrm{g} / \mathrm{mL})$ was added to BEAS-2B cells for $1 \mathrm{~h}$ prior to stimulation with $100 \mu \mathrm{g} / \mathrm{mL}$ of . proliferatum extracts for $24 \mathrm{~h}$. The supernatant was collected and the secretion of CXCL-8 determined by ELISA; (b) BEAS-2B cells were pre-incubated with curdlan at the indicated concentrations for $1 \mathrm{~h}$. Cells were then exposed to F. proliferatum extracts for $24 \mathrm{~h}$ and the amounts of CXCL-8 in the cultured supernatants were determined by ELISA. The results are representative of three (a) and two (b) independent experiments performed in duplicate. Asterisks $\left(^{*}\right)$ indicate significant differences $(p<0.05)$ between the paired samples.

\subsection{Role of Dectin-1/Spleen Tyrosine Kinase in the Fusarium proliferatum Extract-Induced CXCL-8 Release}

Curdlan has been identified as a Dectin-1 specific ligand [12]. To determine whether a Dectin-1 like receptor is involved in the F. proliferatum-induced CXCL-8 release, we used antibodies against human Dectin-1 to examine its effect on CXCL-8 release. BEAS-2B cells were pre-treated with anti-Dectin-1 $(2 \mu \mathrm{g} / \mathrm{mL})$ for $1 \mathrm{~h}$ before exposure to F. proliferatum extracts for $24 \mathrm{~h}$. Results showed that CXCL-8 release decreased by $24 \%$ compared to that of cells without antibody pre-treatment (Figure $4 \mathrm{a}$ ).

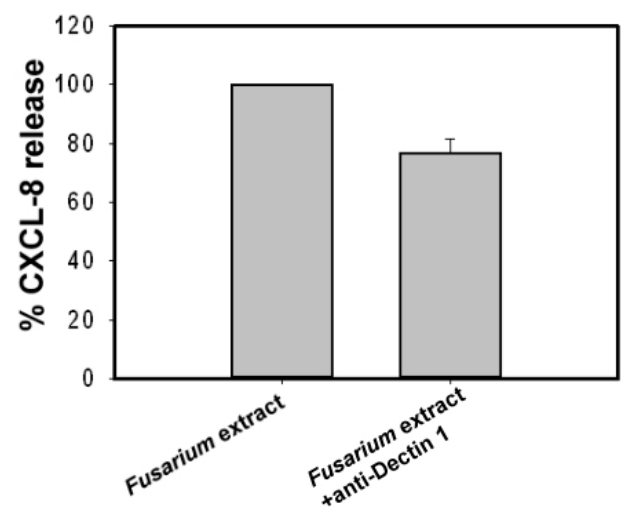

(a)

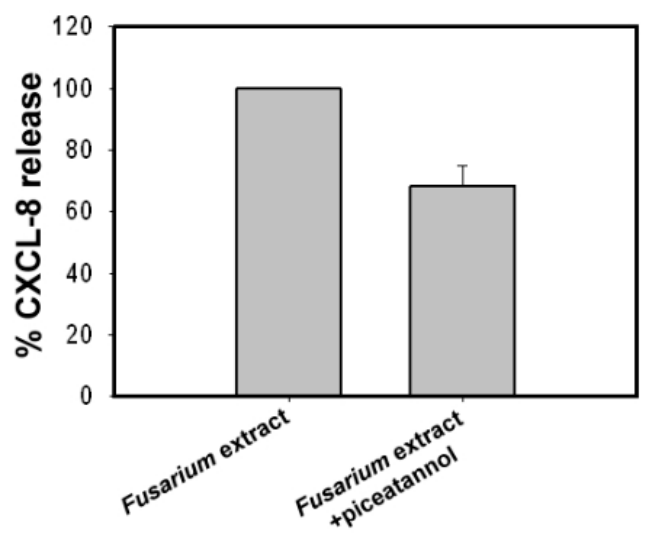

(b)

Figure 4. Effect of the anti-Dectin 1 and Syk specific inhibitor piceatannol on F. proliferatum stimulated CXCL-8 release. BEAS-2B cells were pre-incubated in the absence or presence of mouse monoclonal antibody against human Dectin-1 $(2 \mu \mathrm{g} / \mathrm{mL})$ (a) or Syk inhibitor piceatannol $(5 \mu \mathrm{M})$ (b) for $1 \mathrm{~h}$. Cells were then exposed to F. proliferatum extracts for $24 \mathrm{~h}$ and cultured supernatants were collected for CXCL-8 determination by ELISA. Results are representative of three independent experiments performed in duplicate.

Spleen tyrosine kinase (Syk) is involved in Dectin-1 signaling and plays an important role in antifungal immune responses [13-15]. To assess whether CXCL-8 release from BEAS-2B cells exposed 
to F. proliferatum extracts is dependent on Syk signaling, a Syk inhibitor was used to examine its contribution to this pathway. BEAS-2B cells were incubated with F. proliferatum extracts in the presence or absence of $5 \mu \mathrm{M}$ piceatannol. Results shown in Figure $4 \mathrm{~b}$ indicate that the Syk inhibitor reduced F. proliferatum extracts-induced CXCL-8 secretion by $32 \%$.

2.4. Involvement of the Mitogen-Activated Protein Kinases, phosphatidylinositol-3-kinase and Nuclear Factor $\kappa$-Light-Chain-Enhancer of activated B cells in Fusarium proliferatum-Induced CXCL8 Release

To evaluate whether the mitogen-activated protein kinases (MAPKs) signaling pathways are involved in the F. proliferatum-induced CXCL-8 release, we examined the effect of inhibitors on three subfamilies of MAPKs. Cells were pre-incubated individually, with various inhibitors prior to stimulation with F. proliferatum extracts. As shown in Figure 5a, SB202190, a p38 MAPK inhibitor, exhibited the strongest effect and reduced the F. proliferatum-induced CXCL-8 release by $81 \%$ at $10 \mu \mathrm{M}$ $(p<0.01)$. At the same concentration, the MEK1 inhibitor PD98059 and the ERK1/2 inhibitor U0126 reduced the CXCL-8 release by 57\%. The c-Jun NH2-terminal kinase (JNK) inhibitor SP600125 inhibited $53 \%$ of CXCL-8 release at $5 \mu \mathrm{M}$ (Figure 5a). Without the F. proliferatum extracts, none of the inhibitors had any effect on CXCL-8 release (data not shown). These results indicate that ERK1/2, p38 and JNK pathways are involved in CXCL-8 release from BEAS-2B cells stimulated with F. proliferatum extracts.

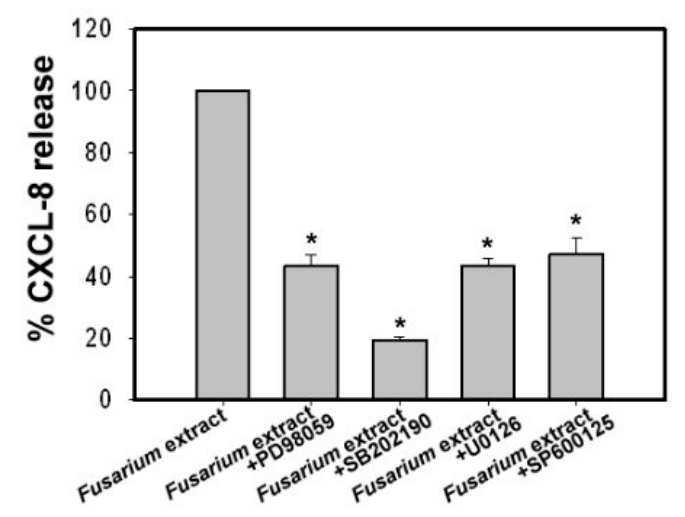

(a)

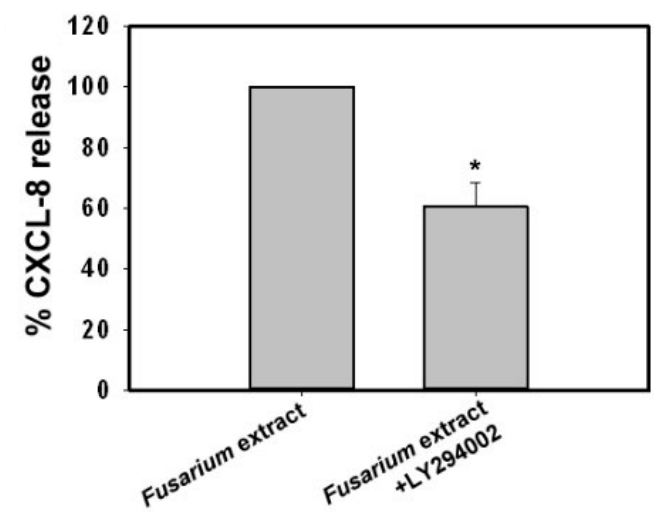

(b)

Figure 5. Effects of mitogen-activated protein kinases (MAPKs) and phosphatidylinositol-3-kinase (PI3K) inhibitor on CXCL-8 release by F. proliferatum-stimulated BEAS-2B cells. BEAS-2B cells were pre-treated in the presence or absence of MAPKs inhibitors PD98059 (MEK1 inhibitor, $10 \mu \mathrm{M}$ ), SB202190 (p38 inhibitor, $10 \mu \mathrm{M}$ ), U0126 (ERK1/2 inhibitor, $10 \mu \mathrm{M}$ ), and SP600125 (JNK inhibitor, $5 \mu \mathrm{M})(\mathbf{a})$ and PI3K inhibitor LY294002 (5 $\mathrm{\mu M})(\mathbf{b})$, respectively, for $1 \mathrm{~h}$ before exposure to F. proliferatum extracts $(100 \mu \mathrm{g} / \mathrm{mL})$ for $24 \mathrm{~h}$. Supernatant was collected and the level of CXCL-8 was determined by ELISA. Results are representative of two independent experiments performed in triplicate. Asterisks $\left(^{*}\right)$ indicate significant differences $(p<0.05)$ between the paired samples.

In addition to MAPKs, a number of protein kinases were also involved in the release of mediators. phosphatidylinositol-3-kinases (PI3K) and its downstream components have been shown to play a prominent role in various inflammatory cells by controlling cell growth, differentiation, survival, proliferation, and cytokine production [16]. In this study, we examined the contribution of PI3K to CXCL-8 release from BEAS-2B cells. The data showed that LY294002 $(5 \mu \mathrm{M})$, a PI3K inhibitor, reduced CXCL-8 release by $40 \%$ (Figure $5 \mathrm{~b}$ ). This result implies that $F$. proliferatum extracts activate the PI3K pathway.

Studies on Dectin-1, Dectin-2 and Mincle have revealed that several signaling components of C-type lectin receptors can induce nuclear factor $\mathrm{k}$-light-chain-enhancer of activated B cells (NF- $\mathrm{kB}$ ) activation [17]. To investigate whether F. proliferatum extracts-induced CXCL-8 release is mediated via NF- $\mathrm{KB}$ activation, BEAS-2B cells were stimulated with $F$. proliferatum extracts in the presence or absence 
of IKB phosphorylation inhibitor BAY117082 (5 $\mu \mathrm{M})$. BAY117082 reduced $26 \%$ of CXCL-8 release at 5 $\mu \mathrm{M}$. Thus, NF- $\mathrm{KB}$ is, at least partially involved in CXCL-8 release from F. proliferatum-treated BEAS-2B cells (Figure 6).

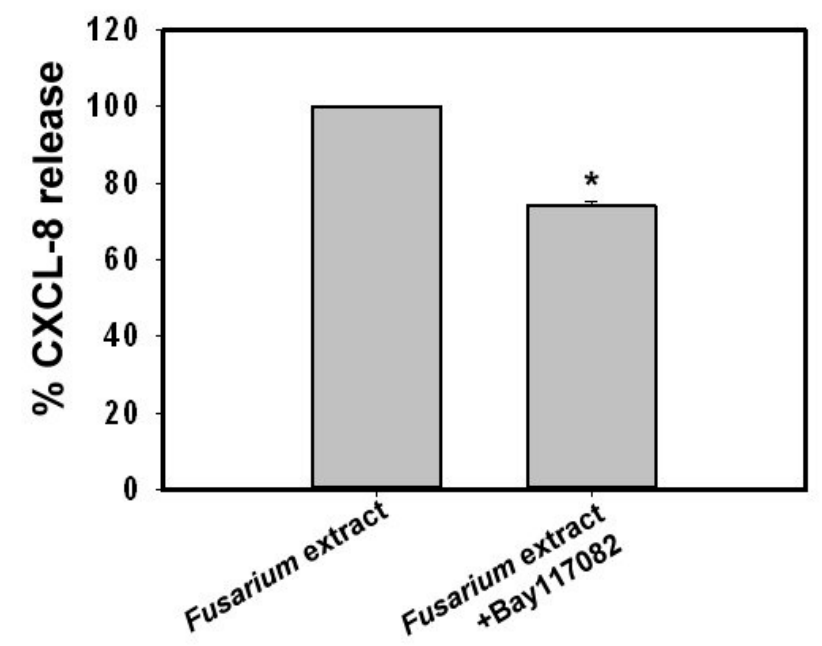

Figure 6. Effect of nuclear factor $\kappa$-light-chain-enhancer of activated B cells (NF- $k B$ ) inhibitor on F. proliferatum-stimulated CXCL-8 release. BEAS-2B cells were pre-incubated with BAY117082 $(5 \mu \mathrm{M})$ for $1 \mathrm{~h}$ before treating with F. proliferatum extracts $(100 \mu \mathrm{g} / \mathrm{mL})$ for $24 \mathrm{~h}$. Cultured supernatants were collected and the level of CXCL- 8 was determined by ELISA. The results are representative of three independent experiments performed in triplicate. Asterisks $\left(^{*}\right)$ indicate significant differences $(p<0.05)$ between the paired samples.

\section{Discussion}

Although Fusarium is one of the prevalent airborne fungi in our environment [18], not much is known about the role of Fusarium species in clinical allergy. Results from the present study showed that stimulation of a human lung epithelial cell line, BEAS-2B cells, with F. proliferatum extracts induces a strong release of the pro-inflammatory and chemotactic factor CXCL-8 in a time-dependent manner (Figures 1 and 2).

During the course of a human cell and fungal interaction, multiple host pattern recognition receptors are likely to be stimulated by different fungal pathogen-associated molecular patterns in different combinations depending on the host cell types and on the fungal species [19]. $\beta$-glucans are a major component of fungal cell walls $[20,21]$. Studies have indicated that $\beta$-glucan may be a target for immune recognition by airway epithelial cells and induces cytokine release via $\beta$-glucan dependent pathways [22-24]. Recently, the $\beta$-glucan receptor Dectin- 1 has been shown to be expressed in human primary normal bronchial epithelium cells and an A549 cell line [25,26]. In this study, our results showed that F. proliferatum extracts-induced CXCL-8 release can be inhibited by Dectin-1 receptor ligands curdlan and laminarin (Figure 3). Curdlan is a linear $(1 \rightarrow 3) \beta$-glucans and laminarin is composed of $(1 \rightarrow 3)(1 \rightarrow 6)-\beta$-glucan linkages. Laminarin is a water soluble small $(6-8 \mathrm{kDa})$ linear $\beta$-glucan with a degree of polymerization of 20-30 which can bind to Dectin- 1 without stimulation of downstream signaling [27-30]. Nevertheless, it can block the binding of larger $\beta$-glucans such as zymosan to Dectin-1 [28], as well as suppress the expression of IL-6 and TNF- $\alpha$ induced by curdlan at both mRNA and protein levels [30]. In this study, laminarin at $10 \mu \mathrm{g} / \mathrm{mL}$ was unable to stimulate CXCL-8 release from BEAS-2B cells alone (data not shown); however, it reduced CXCL-8 release from F. proliferatum-treated BEAS-2B cells to $53 \%$ of the controls without incubation with inhibitors (Figure 3 ). In contrast, curdlan is a long $\beta$-D-glucan with a degree of polymerization of $\sim 500$ [29]. It was found to stimulate mRNA expression of TNF- $\alpha$ and IL-6 in a dose-dependent manner, such as in cultured human corneal epithelial cells [30]. In our preliminary study, curdlan at $100 \mu \mathrm{g} / \mathrm{mL}$ was shown to 
stimulate CXCL-8 release from BEAS-2B cells (data not shown). Therefore, curdlan at $10 \mu \mathrm{g} / \mathrm{mL}$ which was unable to stimulate CXCL-8 release from BEAS-2B cells (data not shown) was used in this study. We found that curdlan $(10 \mu \mathrm{g} / \mathrm{mL})$ significantly reduced CXCL-8 release from F. proliferatum-treated BEAS-2B cells to $20 \%$ of the controls without incubation with inhibitors (Figure 3). Although we did not determine $\beta$-glucans in $F$. proliferatum extracts, the results obtained suggest that there may be $\beta$-glucan structures or some other as yet unidentified Fusarium-derived agents in F. proliferatum extracts, which may contribute to receptor binding and interaction with human airway epithelial cells. With respect to curdlan and laminarin, the Dectin-1 antibody showed less inhibitory effect (Figure 4a). One possible explanation is that $F$. proliferatum extracts bind Dectin- 1 like receptors and others on BEAS-2B cells. Currently, we cannot exclude the possibility that the anti-Dectin-1 used was of low affinity.

Ligation of Dectin- 1 by fungal $\beta$-glucan leads to Syk activation [13-15,31]. Our results show that Syk inhibitor piceatannol $(5 \mu \mathrm{M})$ can diminish F. proliferatum-induced CXCL-8 secretion by $32 \%$. This suggests that interactions between $\beta$-glucan moieties and Dectin- 1 receptors in BEAS-2B cells result in CXCL-8 release.

To further explore molecular mechanisms contributing to F. proliferatum-induced CXCL-8 release, specific inhibitors that block MEK/ERK, p38MAPK, JNK, PI3K and NF- $K B$ activation pathways were used. Our results indicated that PD98059 and U0126 (MEK/ERK inhibitors), SB202190 (p38 MAPK inhibitor) and SP600125 (JNK inhibitor) significantly reduced (>50\%) CXCL-8 release induced by F. proliferatum extracts. In contrast, BAY117082 (I $\mathrm{B}$ inhibitor) was less potent ( $26 \%$ reduction). This suggests that MEK/ERK, p38 MAPK, JNK and NF- $\mathrm{B}$ B pathways are all involved in CXCL-8 release when BEAS-2B cells are stimulated with $F$. proliferatum extracts. In addition, PI3K was also observed to be involved in CXCL-8 release, and indicates that $F$. proliferatum extracts induce CXCL-8 release via multiple signaling pathways. Based on these results, it can be said that innate receptors and signaling pathways contribute to F. proliferatum-induced CXCL-8 release from BEAS-2B cells.

Results obtained from this study indicate that Dectin-1-dependent pathways contribute to F. proliferatum - stimulated pro-inflammatory CXCL-8 chemotactic factor release from lung epithelial BEAS-2B cells. House dust mites (HDM) have been identified as the most important allergens responsible for human atopic diseases worldwide. Interestingly, results from Nathan et al. [24] also suggested that $\beta$-glucan receptors, such as Dectin-1, mediates the activation of the airway epithelium via CCL20 secretion by HDM and may link innate pattern recognition at the airway surface with adaptive immune responses. Fungal spores are ubiquitous in our environment and $\beta$-glucans are a major component of fungal cell walls. Results obtained from this study and others suggest that Dectin-1-mediated signaling (which may be induced through environmental $\beta$-glucan structures or some other as yet unidentified agents exposure including those from fungi and house dust mite) may contribute to the initiation of early allergic airway responses and trigger atopic exacerbation. These findings provide the basis for developing novel therapeutic strategies in clinical allergy.

\section{Materials and Methods}

\subsection{Materials}

Curdlan, laminarin, piceatannol, Bay117082 and SP600125 were purchased from Sigma-Aldrich (Chemical Co., St. Louis, MO, USA); PD98059 and U0126 were purchased from Cell Signaling Technology (Beverly, MA, USA); SB202190 was purchased from Calbiochem (Merck KGaA, Darmstadt, Germany); and mouse anti-human Dectin 1 was purchased from R \& D systems, Inc. (Minneapolis, MN, USA).

\subsection{Crude Extracts of Fusarium proliferatum}

The F. proliferatum strain BCRC 30972 used in this study was isolated from the air of Taiwan and provided by the Food Industry Research and Development Institute, Hsinchu, Taiwan. It was cultured in a CYB medium, without agitation at $26^{\circ} \mathrm{C}$ for 5 days. The CYB medium contains a yeast carbon 
base (Difco Laboratories, Detroit, MI, USA; 11.7 g/L), glucose (Mallinckrodt Baker, Inc., Phillipsburg, NJ, USA; $10 \mu \mathrm{g} / \mathrm{L}$ ) and casein enzymatic hydrolysate (Sigma-Aldrich; $10 \mu \mathrm{g} / \mathrm{L}$ ). Fungal spores and mycelia were collected and ground under liquid nitrogen with a mortar and pestle and the crude extracts were prepared essentially as described in References $[8,10,32]$. The protein content of crude fungal extracts was determined with a dye-binding assay according to the manufacturer's instructions (Bio-Rad, Richmond, CA, USA).

\subsection{Cell Culture and Treatment}

Human bronchial epithelial BEAS-2B cell line (bronchial epithelia, adenovirus 12-SV40 transformed) was obtained from the American Type Culture Collection (ATCC, Manassas, VA, USA). BEAS-2B cells were cultured at $37^{\circ} \mathrm{C}$ in an atmosphere of $5 \% \mathrm{CO}_{2}$ in RPMI-1640 (Life Technologies Gibco BRL, Grand Island, NY, USA), supplemented with $10 \%$ heat-inactivated fetal calf serum (Hyclone, Logan, UT, USA) and antibiotics (penicillin $100 \mathrm{U} / \mathrm{mL}$, streptomycin $100 \mu \mathrm{g} / \mathrm{mL}$; Gibco).

BEAS-2B cells were grown in 24-well culture plates (Corning Costar, Corning, NY, USA) to $80 \%-90 \%$ confluency. Cells were washed three times with Hank's balanced salt solution (Sigma-Aldrich) before treating with F. proliferatum extracts. For mechanism studies, cells were pre-treated with specific inhibitors for $1 \mathrm{~h}$, including PD98059 $(10 \mu \mathrm{M}), \mathrm{SB} 202190(10 \mu \mathrm{M})$, U0126 $(10 \mu \mathrm{M}), \mathrm{SP} 600125(5 \mu \mathrm{M}), \mathrm{LY} 294002(5 \mu \mathrm{M}), \mathrm{BAY} 117082(5 \mu \mathrm{M})$, piceatannol $(5 \mu \mathrm{M})$, and then treated with F. proliferatum extracts $(100 \mu \mathrm{g} / \mathrm{mL})$ for $24 \mathrm{~h}$ in a serum-free medium. In polysaccharide and antibody-blocking experiments, $\beta$-glucan moieties (curdlan $10 \mu \mathrm{g} / \mathrm{mL}$, laminarin $10 \mu \mathrm{g} / \mathrm{mL}$ ) or mouse anti-human Dectin-1 antibodies $(2 \mu \mathrm{g} / \mathrm{mL})$ were used as competitive inhibitors. Cell culture supernatants were collected and stored at $-80{ }^{\circ} \mathrm{C}$ for cytokine assays.

\subsection{Cytokine Array and CXCL-8 ELISA Assay}

F. proliferatum-stimulated cell culture supernatants were analyzed for IL-1A, IL1- $\beta$, IL-2, IL-4, IL-6, CXCL-8, IL-10, IL-12, IL-17A, TNF- $\alpha$, IFN- $\gamma$, and GM-CSF using a Human Inflammatory Cytokines Multi-Analyte ELISArray ${ }^{\mathrm{TM}}$ Kit (SABiosciences, Frederick, MD, USA) according to the manufacturer's instructions. The level of CXCL-8 was measured using a commercially available ELISA kit (R \& D Systems) in accordance with the manufacturer's instructions.

\subsection{Statistical Analyses}

Data were presented as mean \pm SD from at least two independent experiments. Statistical analysis of the data was performed using Student's $t$ test and values were considered statistically significant when the $p$-value was $<0.05$.

\section{Conclusions}

Results obtained from this study suggest that the $\beta$-glucan moieties or some other as yet unidentified agents of $F$. proliferatum interact with the Dectin-1 receptor of airway epithelial cells and activate the Syk, MAPKs, PI3K and NF- $\mathrm{kB}$ signaling pathways to induce CXCL-8 release. This may contribute to the initiation of early allergic airway responses and trigger atopic exacerbation and provides an important basis for developing novel therapeutic strategies in clinical allergy.

Acknowledgments: This work was supported by grants from the Ministry of Science and Technology (NSC 101-2320-B-075-005-MY2; MOST 103-2314-B-010-043-MY3, and MOST 103-2314-B-075-057-MY2) and the Taipei Veterans General Hospital (Grant V103C-034; V103E4-003; V103C-112: V104C-095; V106C-129; and V106D23-001-MY2-1), Taipei, Taiwan. The funders had no role in the study design, data collection and analysis, decision to publish, or preparation of the manuscript. We thank the Clinical Research Core Laboratory and the Medical Science \& Technology Building of the Taipei Veterans General Hospital for providing experimental space and facilities. We would like to thank Ming F. Tam at the Department of Biological Sciences, Carnegie Mellon University, Pittsburgh, PA, USA for his critical reading and review this manuscript.

Author Contributions: Chang-Ching Yeh designed the study, performed the experiments, analyzed the data, and drafted the manuscript. Huann-Cheng Horng revised the paper. Hong Chou designed the study, performed the 
experiments, analyzed the data, and helped to draft the manuscript. Hsiao-Yun Tai analyzed the data, and helped to draft the manuscript. Shie-Liang Hsieh revised the paper. Horng-Der Shen participated in the study design, and helped to analyze the data and revise the draft. Peng-Hui Wang designed the study, analyzed the data, edited the paper and supervised research. All authors read and approved the final manuscript.

Conflicts of Interest: The authors declare no conflict of interest.

\section{Abbreviations}

$\begin{array}{ll}\text { Syk } & \text { Spleen tyrosine kinase } \\ \text { MAPKs } & \text { Mitogen-activated protein kinases } \\ \text { PI3K } & \text { Phosphatidylinositol-3-kinase } \\ \text { HDM } & \text { House dust mite }\end{array}$

\section{References}

1. Sharpe, R.A.; Bearman, N.; Thornton, C.R.; Husk, K.; Osborne, N.J. Indoor fungal diversity and asthma: A meta-analysis and systematic review of risk factors. J. Allergy Clin. Immunol. 2015, 135, 110-122. [CrossRef] [PubMed]

2. Simon-Nobbe, B.; Denk, U.; Pöll, V.; Rid, R.; Breitenbach, M. The spectrum of fungal allergy. Int. Arch. Allergy Immunol. 2008, 145, 58-86. [CrossRef] [PubMed]

3. Lehrer, S.B.; Aukrust, L.; Salvaggio, J.E. Respiratory allergy induced by fungi. Clin. Chest 1983, 4, $23-41$.

4. Kauffman, H.F. Interaction of environmental allergens with airway epithelium as a key component of asthma. Curr. Allergy Asthma Rep. 2003, 3, 101-108. [CrossRef] [PubMed]

5. Tai, H.Y.; Tam, M.F.; Chou, H.; Peng, H.J.; Su, S.N.; Perng, D.W.; Shen, H.D. Pen ch 13 allergen induces secretion of mediators and degradation of occludin protein of human lung epithelial cells. Allergy 2006, 61, 382-388. [CrossRef] [PubMed]

6. Kauffman, H.F.; Tomee, J.F.; van der Werf, T.S.; de Monchy, J.G.; Koëter, G.K. Review of fungus-induced asthmatic reactions. Am. J. Respir. Crit. Care Med. 1995, 151, 2109-2115. [CrossRef] [PubMed]

7. Carsin, A.; Mazenq, J.; Ilstad, A.; Dubus, J.C.; Chanez, P.; Gras, D. Bronchial epithelium in children: A key player in asthma. Eur. Respir. Rev. 2016, 25, 158-169. [CrossRef] [PubMed]

8. Chou, H.; Wu, K.G.; Yeh, C.C.; Tai, H.Y.; Tam, M.F.; Chen, Y.S.; Shen, H.D. The transaldolase, a novel allergen of Fusarium proliferatum, demonstrates IgE cross-reactivity with its human analogue. PLoS ONE 2014, 9, e103488. [CrossRef] [PubMed]

9. Stroud, R.; Calhoun, K.; Wright, S.; Kennedy, K. Prevalence of hypersensitivity to specific fungal allergens as determined by intradermal dilutional testing. Otolaryngol. Head Neck Surg. 2001, 125, 491-494. [CrossRef]

10. Yeh, C.C.; Tai, H.Y.; Chou, H.; Wu, K.G.; Shen, H.D. Vacuolar serine protease is a major allergen of Fusarium proliferatum and an IgE-cross reactive pan-fungal allergen. Allergy Asthma Immunol. Res. 2016, 8, 438-444. [CrossRef] [PubMed]

11. Yeh, C.-C.; Horng, H.-C.; Chou, H.; Tai, H.-Y.; Shen, H.-D.; Hsieh, S.-L.; Wang, P.-H. Department of Obstetrics and Gynecology, Taipei Veterans General Hospital, Taipei 112, Taiwan. BEAS-2B cells and Fusarium proliferatum extracts. 2016.

12. Mocanu, G.; Mihai, D.; Moscovici, M.; Picton, L.; LeCerf, D. Curdlan microspheres. Synthesis, characterization and interaction with proteins (enzymes, vaccines). Int. J. Biol. Macromol. 2009, 44, 215-221. [CrossRef] [PubMed]

13. Osorio, F.; Reise Sousa, C. Myeloid C-type lectin receptors in pathogen recognition and host defense. Immunity 2011, 34, 651-664. [CrossRef] [PubMed]

14. Kerrigan, A.M.; Brown, G.D. Syk-coupled C-type lectins in immunity. Trends Immunol. 2011, 32, 151-156. [CrossRef] [PubMed]

15. Saijo, S.; Wakura, Y. Dectin-1 and Dectin-2 in innate immunity against fungi. Int. Immunol. 2011, $23,467-472$. [CrossRef] [PubMed]

16. Koyasu, S. The role of PI3K in immune cells. Nat. Immunol. 2003, 4, 313-319. [CrossRef] [PubMed]

17. Kingeter, L.M.; Lin, X. C-type lectin receptor-induced NF- $\mathrm{KB}$ activation in innate immune and inflammatory responses. Cell Mol. Immunol. 2012, 9, 105-112. [CrossRef] [PubMed] 
18. Amend, A.S.; Seifert, K.A.; Samson, R.; Bruns, T.D. Indoor fungal composition is geographically patterned and more diverse in temperate zones than in the tropics. Proc. Natl. Acad. Sci. USA 2010, 107, 13748-13753. [CrossRef] [PubMed]

19. Romani, L. Immunity to fungal infections. Nat. Rev. Immunol. 2011, 11, 275-288. [CrossRef] [PubMed]

20. Douwes, J. (1 $\rightarrow 3)-\beta$-D-glucans and respiratory health: A review of the scientific evidence. Indoor Air 2005, 15, 160-169. [CrossRef] [PubMed]

21. Schoffelmeer, E.A.; Klis, F.M.; Sietsma, J.H.; Cornelissen, B.J. The cell wall of Fusarium oxysporum. Fungal Genet. Biol. 1999, 27, 275-282. [CrossRef] [PubMed]

22. Carmona, E.M.; Lamont, J.D.; Xue, A.; Wylam, M.; Limper, A.H. Pneumocystis cell wall $\beta$-glucan stimulates calcium-dependent signaling of IL-8 secretion by human airway epithelial cells. Respir. Res. 2010, 11, 95-106. [CrossRef] [PubMed]

23. Neveu, W.A.; Bernardo, E.; Allard, J.L.; Nagaleekar, V.; Wargo, M.J.; Davis, R.J.; Iwakura, Y.; Whittaker, L.A.; Rincon, M. Fungal allergen $\beta$-glucans trigger p38 mitogen-activated protein kinase-mediated IL- 6 translation in lung epithelial cells. Am. J. Respir. Cell Mol. Biol. 2011, 45, 1133-1141. [CrossRef] [PubMed]

24. Nathan, A.T.; Peterson, E.A.; Chakir, J.; Wills-Karp, M. Innate immune responses of airway epithelium to house dust mite are mediated through $\beta$-glucan-dependent pathways. J. Allergy Clin. Immunol. 2009, 123, 612-618. [CrossRef] [PubMed]

25. Sun, W.K.; Lu, X.; Li, X.; Sun, Q.Y.; Su, X.; Song, Y.; Sun, H.M.; Shi, Y. Dectin-1 is inducible and plays a crucial role in Aspergillus-induced innate immune responses in human bronchial epithelial cells. Eur. J. Clin. Microbiol. Infect. Dis. 2012, 31, 2755-2764. [CrossRef] [PubMed]

26. Heyl, K.A.; Klassert, T.E.; Heinrich, A.; Müller, M.M.; Klaile, E.; Dienemann, H.; Grünewald, C.; Bals, R.; Singer, B.B.; Slevogt, H. Dectin-1 is expressed in human lung and mediates the proinflammatory immune response to nontypeable Haemophilus influenzae. MBio 2014, 5, e01492-14. [CrossRef] [PubMed]

27. Goodridge, H.S.; Wolf, A.J.; Underhill, D.M. $\beta$-Glucan recognition by the innate immune system. Immunol. Rev. 2009, 230, 38-50. [CrossRef] [PubMed]

28. Goodridge, H.S.; Reyes, C.N.; Becker, C.A.; Katsumoto, T.R.; Ma, J.; Wolf, A.J.; Bose, N.; Chan, A.S.H.; Magee, A.S.; Danielson, M.E.; et al. Activation of the innate immune receptor Dectin-1 upon formation of a "phagocytic synapse". Nature 2011, 472, 471-475. [CrossRef] [PubMed]

29. Kataoka, K.; Muta, T.; Yamazaki, S.; Takeshige, K. Activation of macrophages by linear (1right-arrow3)- $\beta$-D-glucan. Impliations for the recognition of fungi by innate immunity. J. Biol. Chem. 2002, 277, 36825-36831. [CrossRef] [PubMed]

30. Zhu, C.C.; Zhao, G.Q.; Lin, J.; Hu, L.T.; Xu, Q.; Peng, X.D.; Wang, X.; Qiu, S. Dectin-1 agonist curdlan modulates innate immunity to Aspergillus fumigatus in human corneal epithelial cells. Int. J. Ophthalmol. 2015, 8, 690-696. [PubMed]

31. Brown, G.D.; Herre, J.; Williams, D.L.; Willment, J.A.; Marshall, A.S.; Gordon, S. Dectin-1 mediates the biological effects of $\beta$-glucans. J. Exp. Med. 2003, 197, 1119-1124. [CrossRef] [PubMed]

32. Shen, H.D.; Lin, W.L.; Tam, M.F.; Wang, S.R.; Tzean, S.S.; Huang, M.H.; Han, S.H. Characterization of allergens from Penicillium oxalicum and P. notatum by immunoblotting and $\mathrm{N}$-terminal amino acid sequence analysis. Clin. Exp. Allergy 1999, 29, 642-651. [CrossRef] [PubMed]

(C) 2017 by the authors. Licensee MDPI, Basel, Switzerland. This article is an open access article distributed under the terms and conditions of the Creative Commons Attribution (CC BY) license (http://creativecommons.org/licenses/by/4.0/). 